\title{
Early detection of bacterial growth in blood culture by impedance monitoring with a Bactometer model 32
}

\author{
ANNE BUCKLAND, STUART KESSOCK-PHILIP, SHOSHANA BASCOMB \\ From the Department of Medical Microbiology, St Mary's Hospital Medical School, London, W2 1PG
}

SUMMARY A Bactometer model 32 was evaluated for use in early detection of bacterial growth. Experiments with simulated cultures showed that $2 \mathrm{ml}$ of broth introduced into the Bactometer module wells could detect $10^{2}$ and $10^{6} \mathrm{CFU} / \mathrm{ml}$ in $6 \mathrm{~h}$ and $2 \mathrm{~h}$ respectively. Both Brain Heart Infusion (BHI) and Fastidious Anaerobic broths supported good growth. Detection of nine of 10 organisms inoculated at approximately $10^{6} \mathrm{CFU} / \mathrm{ml}$ in $\mathrm{BHI}$ were detected within $8.5 \mathrm{~h}$. A culture of Bacteroides fragilis failed to grow under these conditions. Of 189 blood cultures, tested by incubation of $2 \mathrm{ml}$ of $\mathrm{BHI}, 18$ were positive by both conventional and Bactometer methods. False-positive or false-negative specimens were not observed using the Bactometer. Use of the Bactometer enables growth detection at least $12 \mathrm{~h}$ earlier than culture methods.

Rapid detection of septicaemia is of primary importance in the diagnostic laboratory. Immediate Gram staining of blood specimens can detect approximately $10^{5}$ organisms $/ \mathrm{ml}$. However, culture methods are necessary to detect pathogens present at lower concentrations. Conventional methods rely on culturing of blood specimens and detection of growth by subculturing and Gram staining requiring 18-24 $h$ for the first observation, negative cultures being kept for seven days or more. More sensitive methods are therefore sought for faster detection of positive blood cultures. Newer detection methods available were reviewed by Bascomb. ${ }^{1}$ Methods applied for detection of septicaemia include radiometric techniques ${ }^{2}$ measurement of bacterial $\mathrm{ATP}^{3}$ and monitoring of impedance changes. ${ }^{4-6} \mathrm{~A}$ number of impedance measuring devices have been described. ${ }^{1}$ The Bactometer ${ }^{7}$ is commercially available and has been used for detection of bacteriuria ${ }^{89}$ and in the food industry ${ }^{10}$ and sewage effluent monitoring. ${ }^{11}$ Its use in detection of septicaemia has been limited.124-6 We have evaluated the Bactometer model 32 as to its suitability for monitoring growth of bacteria in blood cultures from the diagnostic laboratory. We also investigated the effects of type and volume of medium, concentration of inoculum, and the applicability of the instrument to the variety of organisms likely to be found in blood cultures.

\section{Material and methods}

\section{CULTURE MEDIA}

Two blood culture media were used. Brain Heart Infusion broth (BHI) + thymidine + sodium polyanethyl sulphonate (SPS) and Fastidious Anaerobic broth (FAB) + thymidine, both supplied by Lab M, Salford, Lancs.

\section{TEST CULTURES}

All strains were recent laboratory isolates identified by standard technique. ${ }^{13}$

\section{BLOOD CULTURES}

Five $\mathrm{ml}$ of patient's blood was inoculated into $75 \mathrm{ml}$ of BHI and FAB bottles on the ward. The blood culture set was brought to the laboratory immediately and incubated at $37^{\circ} \mathrm{C}$. $\beta$-lactamase $(0.5 \mathrm{ml})$ (Genzyme Biochemicals) was added to each bottle if the patient was receiving a $\beta$-lactam antibiotic. All blood cultures were subcultured onto blood agar anaerobically and chocolate agar in $7 \% \mathrm{CO}_{2}$ after $24 \mathrm{~h}, 48 \mathrm{~h}$ and seven days incubation at $37^{\circ} \mathrm{C}$. Any turbid bottle after $24 \mathrm{~h}$ incubation had a Gram film made and examined.

\section{VIABLE COUNTS}

Miles and Misra counts ${ }^{14}$ were performed on the experimental broth cultures.

IMPEDANCE MEASUREMENTS

The Bactometer consists of a thermostatically con- 
trolled monitoring unit. Four plastic modules (100 $\times 75 \mathrm{~mm}$ ) each having eight pairs of rectangular wells can be accommodated in the incubator. Each well contains a pair of electrodes that are connected to the monitoring unit via metal strips on the underside of the module. The metal strips converge in a tab that is plugged into the incubator.

The modules come in a sterile plastic envelope, the wells of which are covered by a plastic film, through which broth can be introduced aseptically with a syringe and needle. After filling, another sterile adhesive film supplied with each module, is placed over the wells to seal the needle holes.

Each well can hold $2.5 \mathrm{ml}$ of broth but, to avoid overfilling, $2.0 \mathrm{ml}$ was used. The lower row of wells, filled with sterile broth, were used as reference, the upper row of wells were filled with inoculated broth or media taken from inoculated blood cultures.

All eight wells of the module need not be filled before monitoring commences, further cultures can be added as and when they arrive in the laboratory.

Monitoring of impedance can also be achieved by inserting Bactometer electrodes into conventional growth vessels. These are reusable autoclavable electrodes that are incorporated into a screw cap that can replace the cap of the blood culture bottle. This enables the bottles to be connected to an extension socket inside an ordinary incubator which relays information back to the Bactometer. Each blood culture bottle requires a reference bottle of sterile broth with inserted electrodes. The electrodes can be reused about 30 times.

The impedance changes are shown as a trace on a chart recorder. Each trace is a representation of a growth curve. To fit 32 curves onto one width of a chart recorder paper, each curve is divided into segments $8 \mathrm{~mm}$ wide (Fig. 1a). The rate at which the trace traverses a channel width gives an indication of the rate of growth (Fig. 1b).

Bacterial growth is represented by the trace traversing a channel width from left to right whereas yeasts produce the opposite effect.

\section{Results}

\section{RANGE OF ORGANISMS DETECTABLE BY THE BACTOMETER}

Cultures of 10 organisms likely to be found in blood (Table 1) were inoculated into BHI to give an approximate concentration of $1 \times 10^{6} \mathrm{CFU} / \mathrm{ml}$. Two $\mathrm{ml}$ of each broth were transferred to the wells in the top row of the module and $2.0 \mathrm{ml}$ of sterile $\mathrm{BHI}$ into the reference wells. The modules were monitored on the Bactometer for $48 \mathrm{~h}$ for signs of growth.

As can be seen from Fig. 1c there is an initial period, ranging from 0.5 to $3 \mathrm{~h}$, in which the traces repeatedly traverse the channel width in either direction, they then flatten out but still tend to drift slightly. This response, seen in all the blood cultures examined, is thought not to be due to growth but rather to the erythrocytes settling to the bottom of the well.

The periods in which growth responses were observed varied from 5 to $18 \mathrm{~h}$, and in two cultures, Clostridum perfringens and Staphylococcus epidermidis two growth periods were observed, with a period of several hours of no growth in between.

All but one of the organisms selected showed growth within $8.5 \mathrm{~h}$. The times for appearance of detectable growth are shown in Table 1 . The failure to detect growth of Bacteroides is probably due to the poor anaerobic conditions in the small volume of broth.

\section{EFFECT OF INOCULUM SIZE ON SPEED OF DETECTION}

Dilutions of Escherichia coli, Haemophilus inftuenzae and Staphylococcus aureus were prepared in BHI to give initial concentrations of approximately $1 \times 10^{2}, 1 \times 10^{4}$ and $1 \times 10^{6} \mathrm{CFU} / \mathrm{ml}$. Viable counts $^{14}$ were performed on these broths to establish the exact concentrations. All wells were monitored for $6 \mathrm{~h}$. As can be seen from Fig. 2 there is a good correlation between inoculum size and detection time; $10^{7} \mathrm{CFU} / \mathrm{ml}$ were detected in $1.5 \mathrm{~h}, 10^{2} \mathrm{CFU} /$ $\mathrm{ml}$ in $6 \mathrm{~h}$.

\section{EFFECT OF CULTURE MEDIA ON SPEED OF DETECTION}

Eight blood cultures were chosen to show differences between the FAB and BHI media. They were monitored for $48 \mathrm{~h}$ and their traces examined. Six blood cultures showed no response, two showed a growth response. The duration and the shape of the growth curves were the same for both media.

\section{DETECTION OF GROWTH IN BLOOD CULTURE SPECIMENS}

One hundred and eighty nine blood cultures were examined during a period of four weeks. A $2.0 \mathrm{ml}$ aliquot was drawn from the BHI bottle with a syringe and needle for examination on the Bactometer as described above. These cultures were monitored for $48 \mathrm{~h}$ before being discarded. Complete agreement was found between growth and impedance methods. Eighteen specimens were found to be positive by both methods. The remaining 171 were found to be negative by both. The list of species isolated is given in Table 3 . The majority of cultures were detected within $3 \mathrm{~h}$. One specimen containing Streptococcus pyogenes was detected after $4.5 \mathrm{~h}$, two specimens containing Staphylococ- 
(a)

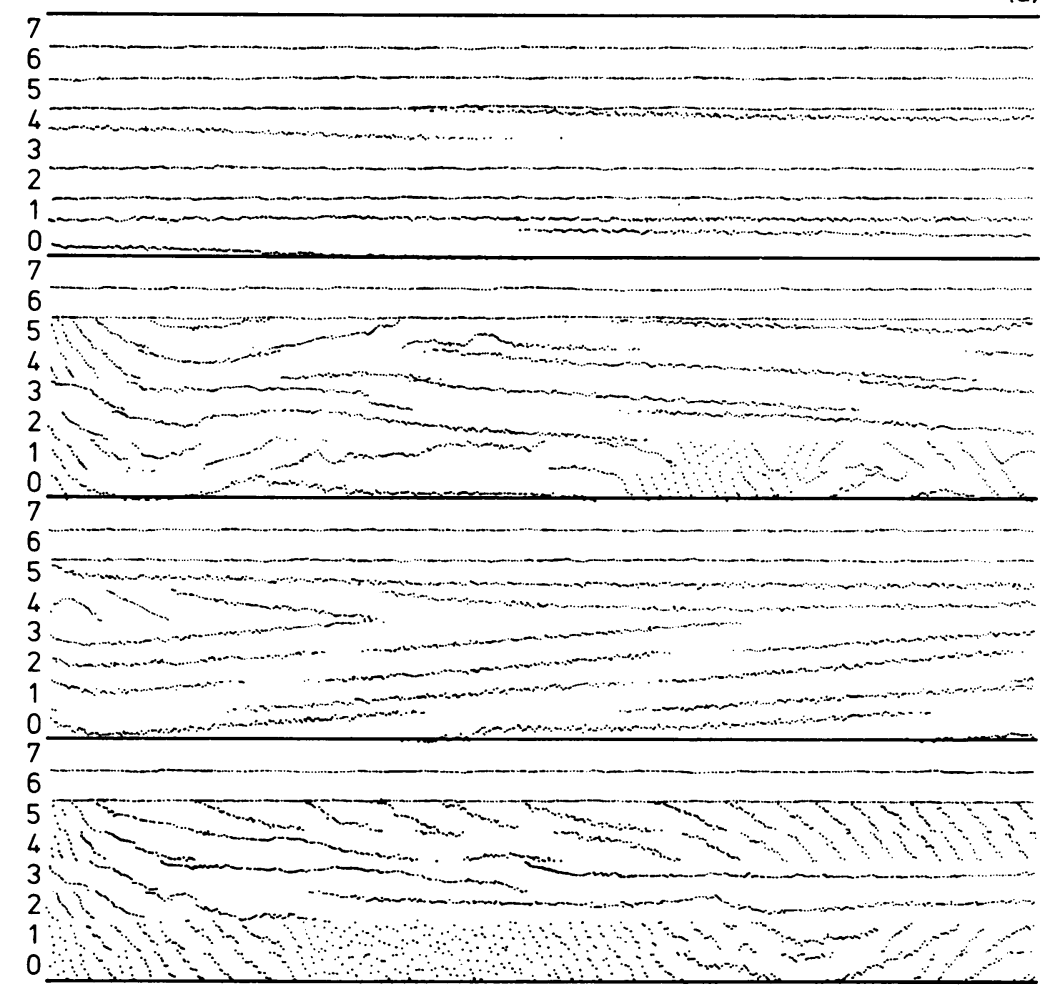

(b)

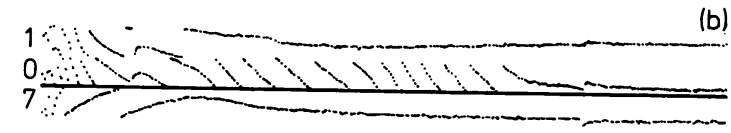

(c)

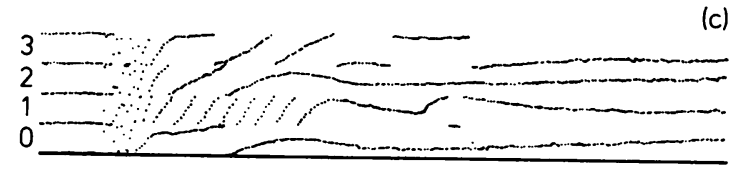

Fig. 1 Traces of impedance monitoring obtained with Bactometer 32*. (a) A typical Bactometer chart showing the recording of 32 cultures. It is divided into four horizontal sections, each section is labelled from 0 to 7 representing the eight cultures in one module. (b) The centre trace shows a growth curve response. It demonstrates a short settling down period followed by a stationary phase and growth response. The lines get closer together as growth accelerates into the logarithmic phase. The other traces show no growth response. (c) The traces of four sterile blood cultures show how the settling down periods can vary in shape and duration. *For clarity of reproduction the Bactometer chart grid has been erased. 
Table 1 Taxa detected by Bactometer

\begin{tabular}{ll}
\hline & $\begin{array}{l}\text { Time for } \\
\text { initial detection }(h)\end{array}$ \\
\hline Staphylococcus aureus & 1 \\
Staphylococcus epidermidis & $1 / 2$ \\
Streptococcus pneumoniae & $2^{1 / 2}$ \\
Streptococcus pyogenes & $8^{1 / 2}$ \\
Streptococcus mitior & $1^{11 / 2}$ \\
Escherichia coli & $3^{1 / 2}$ \\
Haemophilus infuenzae & 5 \\
Candida albicans & $3^{1 / 2}$ \\
Clostridium perfringens & (failed to grow) \\
Bacteroides fragilis &
\end{tabular}

Table 2 Effect of broth volume on time for initial detection of growth (h)

\begin{tabular}{llllll}
\hline & \multicolumn{6}{l}{ Volume of broth $(\mathrm{ml})$} \\
\cline { 2 - 6 } & $0 \cdot 5$ & $1 \cdot 0$ & $1 \cdot 5$ & $2 \cdot 0$ & $2 \cdot 5$ \\
\hline Staphylococcus aureus & $41 \frac{1}{2}$ & $41 / 2$ & 4 & $31 / 4$ & $31 / 4$ \\
Streptococcus pyogenes & $4^{1 / 2}$ & $3^{3 / 4}$ & $3^{1 / 4}$ & 3 & $2^{3 / 4}$ \\
Haemophilus inftuenzae & 4 & 4 & 4 & $31 / 2$ & $31 / 2$ \\
\hline
\end{tabular}

cus epidermidis and Staphylococcus aureus were detected after $8 \mathrm{~h}$, and two specimens containing Staphylococcus epidermidis and Streptococcus mitior were detected after $8 \cdot 5 \mathrm{~h}$.

\section{Discussion}

Monitoring of growth by the Bactometer can be done in the special $2.5 \mathrm{ml}$ capacity wells of the growth modules, or by inserting reuseable sterile electrodes into conventional culture containers. To avoid any danger of contaminating patients' specimens we used the growth modules only, in this preliminary study. Reading of the Bactometer charts is easily acquired though the initial period of settling of blood cells can sometimes confuse the interpretation. It might be useful to investigate further the use of non-ionic detergent for lysis of the blood cells prior to incubation as suggested by Makin and Corkill $^{15}$ to avoid such problems.

Both media used for blood cultures in our laboratory were suitable for use in the Bactometer. In simulated cultures, presence of $10^{2} \mathrm{CFU} / \mathrm{ml}$ could be detected in about $6 \mathrm{~h}$, that of $10^{6}$ in $2 \mathrm{~h}$.

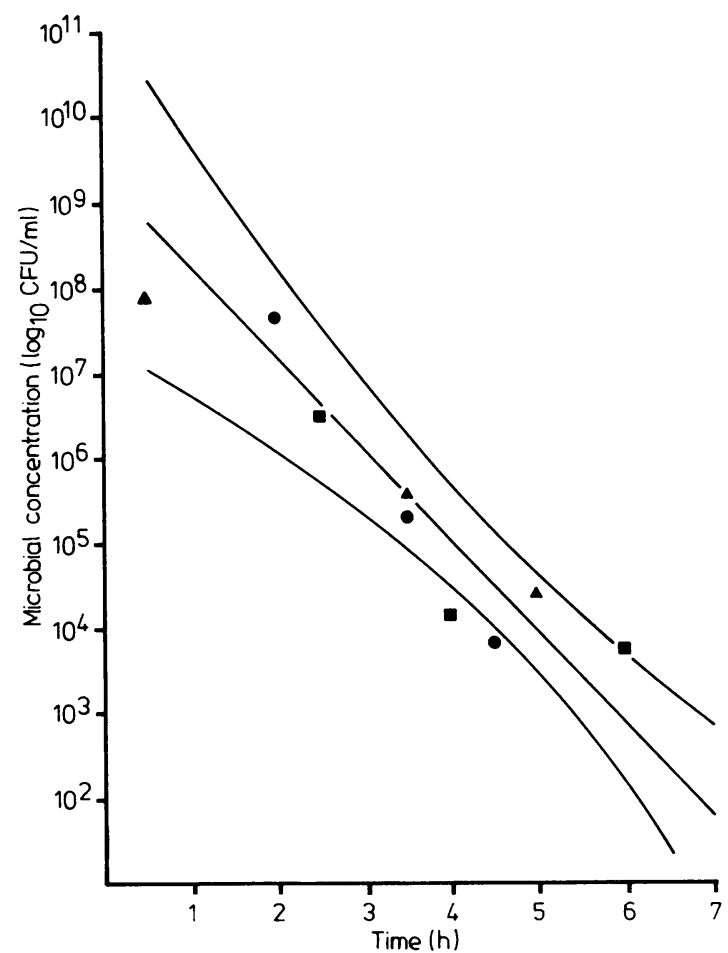

Fig. 2 Relation between initial microbial concentration and impedance response detection time. Two $\mathrm{ml}$ of suspensions of E coli ( $\Delta)$, Staph aureus (O) and Haemophilus infuenzae ( $\mathrm{G}$ ) in BHI were inoculated into Bactometer 32 wells and monitored for impedance change. Microbial concentrations determined by viable counts.

Fitted line $y=8 \cdot 157-1 \cdot 0148 x$ and $95 \%$ confidence limits; $r^{2}=0 \cdot 87908$

Moreover, complete agreement was found between conventional and impedance detection of septicaemia with 189 blood specimens. Most infected cultures being detected by the Bactometer method within $8.5 \mathrm{~h}$, this being at least $10-36 \mathrm{~h}$ earlier than conventional methods, thereby providing a valuable rapid service to the patient.

In simulated cultures nine of 10 different organ- $N$ isms tested were detected within $10 \mathrm{~h}$ of incubation. The culture of Bacteroides fragilis failed to show

Table 3 Bactometer 32 detection time of organisms found in blood cultures

\begin{tabular}{|c|c|c|c|c|c|c|c|c|c|}
\hline \multirow[t]{2}{*}{ Isolates } & \multicolumn{8}{|c|}{ Detection time $(h)$} & \multirow{2}{*}{$\begin{array}{l}\text { Total number } \\
\text { of cultures }\end{array}$} \\
\hline & $0 \cdot 5$ & 1 & $1 \cdot 5$ & 2 & $2 \cdot 5$ & $4 \cdot 5$ & 8 & $8 \cdot 5$ & \\
\hline $\begin{array}{l}\text { Staphylococcus epidermidis } \\
\text { Streptococcus aureus } \\
\text { Streptococcus pneumoniae } \\
\text { Streptococcus pyogenes } \\
\text { Streptococcus mitior } \\
\text { Escherichia coli }\end{array}$ & $\frac{2}{1}$ & $\begin{array}{l}2 \\
2 \\
- \\
-\end{array}$ & $\frac{1}{-}$ & $\begin{array}{l}1 \\
- \\
- \\
-\end{array}$ & $\frac{2}{-}$ & $\frac{-}{-}$ & $\frac{2}{-}$ & $\frac{1}{-}$ & $\begin{array}{r}11 \\
3 \\
1 \\
1 \\
1 \\
1\end{array}$ \\
\hline
\end{tabular}


change in impedance during $48 \mathrm{~h}$ of monitoring, probably owing to insufficient anaerobiosis in the growth well. Over-laying with liquid paraffin might produce better conditions for anaerobic growth, but would probably prove difficult to introduce into the wells through the plastic strip. A better solution might be to insert the Bactomatic electrodes into an anaerobic culture bottle. Detection of growth of Eubacterium limosum and of Fusobacterium nucleatum has been reported.?

In preliminary work with the Bactometer before the study began, a problem was encountered with a blood culture that had been incubated over the weekend before being monitored. It yielded large numbers of bacteria on subculture but showed no change of impedance. This was probably due to the fact that nutrients in the culture media were exhausted during the weekend and metabolism could not therefore be detected by the Bactometer. However, the bacteria present could grow when supplied with new nutrients by subculturing. The Bactometer procedure is therefore not suitable for such specimens. These heavily infected cultures can be quickly detected by Gram staining those bottles which show turbidity. Alternatively, such specimens should be subcultured into fresh broth before Bactometer monitoring.

The model 32 Bactometer system has one serious limitation, the number of cultures it can deal with at one time (32) is too small. As impedance is much affected by temperature it is essential to incubate a reference cell for each culture. If each specimen is tested in both aerobic and anaerobic broth, this reduces the number of specimens to 16 . Moreover, if they need to be kept for up to two days, it allows for only eight blood specimen investigations per day. In our laboratory serving a group of hospitals with a total of 547 beds, an average of 14 blood cultures are processed per day. A machine with greater capacity would be necessary in busy laboratories.

The capital outlay for an instrument is an impor-

Table 4 Comparison of purchase and running costs of Bactometer 32 and Bactec 460

\begin{tabular}{|c|c|c|}
\hline & $\begin{array}{l}\text { Bactometer } \\
\text { (£) }\end{array}$ & $\begin{array}{l}\text { Bactec } \\
(£)\end{array}$ \\
\hline Capital outlay & $9900 \cdot 00$ & $16604 \cdot 00$ \\
\hline $\begin{array}{l}\text { Cost per blood culture } \\
\text { bottle }\end{array}$ & $0 \cdot 35$ & 0.76 \\
\hline $\begin{array}{l}\text { Cost of module per test } \\
\text { ( } 2 \text { wells) }\end{array}$ & 0.45 & \\
\hline Cost of electrode & 1.00 & \\
\hline Cost per patient & $1.60^{*}$ & $1 \cdot 52$ \\
\hline
\end{tabular}

*Based on one bottle and two wells for each medium.

tBased on two bottles of each medium and 1/30th of cost of a reusable electrode.

Prices are exclusive of VAT. tant factor. In Table 4 we have shown the costs of Bactometer against that of the other instrument available for processing blood specimens, the Bactec system. ${ }^{2}$ As can be seen the Bactometer is very much cheaper than the Bactec, whereas the running costs per specimen using the growth modules inoculated from the conventional broth are similar.

At present it would not be safe to replace conventional culturing methods by the Bactometer impedance monitoring, but the instrument might be used concomitantly with the conventional method, cultures being kept for $24 \mathrm{~h}$ only. In this way heavily infected specimens would be detected within the working day and treatment of patients could be started or amended sooner. Cultures not detected within $24 \mathrm{~h}$ would, for the present, have to be handled by conventional methods.

We thank BCJ Levett of Bactomatic Inc, for advice and loan of equipment used in this evaluation.

\section{References}

' Bascomb S. Application of automation to the general and specific detection of bacteria. Lab Practice 1981;30:461-4.

${ }^{2}$ DeBlanc HJ Jr, Deland F, Wagner HN Jr. Automated radiometric detection of bacteria in 2967 blood cultures. Appl Microbiol 1981;22:846-9.

${ }^{3}$ Schrock CG, Barza MJ, Deming JW, Picciolo GL, Chapelle EW, Weinstein L. Rapid detection of bacterial growth in blood cultures by means of adenosine triphosphate determination. In: Abstracts, American Society for Microbiology. Annual Meeting, 1976 Paper No C71:37.

${ }^{4}$ Khan W, Friedman G, Rodriquez W, Controni G, Ross S. Rapid detection and isolation of bacteria in blood and cerebrospinal fluids in children by the electrical impedance method. In: Johnston HH, Newsom SWB, eds. 2nd International symposium on rapid methods and automation in microbiology. Oxford: Learned Information, 1976:13-4.

5 Throm R, Strauss R, Specter S, Friedman H. Automated blood culture testing using radioisotope and electrical impedance monitoring equipment. In: Johnston $\mathrm{HH}$, Newsom SWB, eds. 2nd International symposium on rapid methods and automation in microbiology. Oxford: Learned Information, 1976:21-2.

- Specter S, Throm R, Strauss R, Friedman H. Rapid detection of bacterial growth in blood samples by a continuous-monitoring electrical impedance apparatus. J Clin Microbiol 1977;6:489-93.

' Cady P, Dufour SW, Shaw J, Kraeger SJ. Electrical impedance measurements: rapid method for detecting and monitoring micro-organisms. J Clin Microbiol 1978;7:265-72.

Zafari Y, Martin WJ. Comparison of the Bactometer microbial monitoring system with conventional methods for detection of micro-organisms in urine specimens. J Clin Microbiol 1977;5:545-7.

${ }^{9}$ Cady P, Dufour SW, Lawless P, Nunke B, Kraeger SJ. Impedimetric screening for bacteriuria. J Clin Microbiol 1978;7:273-8.

${ }^{10}$ Martins SB, Selby MJ. Evaluation of a rapid method for the quantitative estimation of coliforms in meat by impedimetric procedures. Appl Environ Microbiol 1980;39:518-24.

"Silverman MP, Munoz EF. Automated electrical impedance technique for rapid enumeration of fecal coliforms in effluents from sewage treatment plants. Appl Environ Microbiol 1979;37:521-6. 
${ }^{12}$ Hadley WK. The use of electrical impedance measurements for detection of microorganisms in blood culture. In: Johnston $\mathrm{HH}$, Newsom SWB, eds. 2nd International symposium on rapid methods and automation in microbiology. Oxford: Learned Information, 1976:14.

${ }^{13}$ Cowan ST. Cowan and Steel's manual for the identification of medical bacteria. 2nd ed. Cambridge: Cambridge University Press, 1974.

${ }^{14}$ Miles AA, Misra SS. The estimation of the bactericidal power of the blood. J Hyg 1938;38:732-49.

is Makin T, Corkill JE. The detection of bacteria in blood cultures by impedance monitoring-a pilot study. Med Lab World 1978:409-15.

Requests for reprints to: Dr S Bascomb, Department of Medical Microbiology, St Mary's Hospital Medical School, London W2 1PG, England.

\section{The June 1983 issue}

\section{THE JUNE 1983 ISSUE CONTAINS THE FOLLOWING PAPERS}

Screening hospital patients for uterine cervical cancer ELIZABETH HUDSON, SHEILA HEWERTSON, C JANSZ, H GORDON

Histopathology of papilloma virus infection of the cervix uteri: the history, taxonomy, nomenclature and reporting of koilocytic dysplasias S FLETCHER

Diagnosis of amniotic fluid embolism using an antiserum to human keratin IWC GARLAND, WD THOMPSON

Epithelial markers in the diagnosis of nasopharyngeal carcinoma: an immunocytochemical study BA GUSTERSON, DIANA P MTCHELL, MJ WARBURTON, RL CARTER

Granulomatous disease in the vermiform appendix DC ALLEN, JD BIGGART

An ultrastructural and immunocytochemical study of a renal carcinoma secreting inactive renin GBM LINDOP, IAR MORE, BRENDA LECKIE

Comparison of the haematoxylin basic fuchsin picric acid method and the fluorescence of haematoxylin and eosin stained sections for the identification of early myocardial infarction HK AL-RUFAIE, RA FLORIO, EGJ OLSEN

Liver histopathology of the hepatitis A virus infection: a comparison with hepatitis type $B$ and non-A, non-B P KRYGER, P CHRISTOFFERSEN

Preliminary report of an association between measles virus and achalasia DB JONES, JF MAYBERRY, J RHODES, JULIA MUNRO

Coxsackie $B$ virus infection in coronary care unit patients D O'NEILL, JD MCARTHUR, JA KENNEDY, G CLEMENTS

Examination of operation specimens from patients with spinal tuberculosis for tubercle bacilli BW ALLEN, DA MITCHISON, JANET DARBYSHIRE, WWK CHEW, M GABRIEL

Attempts to isolate Campylobacter jejuni from various body sites EP WRIGHT

Copies are still available and may be obtained from the PUBLISHING MANAGER.

BRITISH MEDICAL ASSOCIATION, TAVISTOCK SQUARE, LONDON WC1H 9JR. price $£ 5.00$, including postage
Phenomenon of resistance to Augmentin associated with sensitivity to ampicillin: occurrence and explanation W BRUMFITT, JMT HAMILTON-MILLER, SHIRLEY DIXSON, RA GARGAN, ANN GOODING io Diagnosis of urogenital gonorrhoea by detecting $N$ gonococcal antigen with a solid phase enzyme 은 immunoassay (Gonozyme ${ }^{\mathrm{TM}}$ ) D DANIELSSON, H MOI, L FORSLIN

Effect of adding a papain digest of ox liver to brain heart infusion cysteine broth on the recovery of $\mathscr{C}^{\circ}$ non-sporing anaerobes from simulated blood $\omega$ cultures DC SHANSON, JANET PRATT

Problems of infection after bone marrow transplantation J GRAHAM WATSON Increased mean platelet volume in septicaemia $\mathrm{J}$ VAN DER LELIE, AEG KR VON DEM BORNE

A fluorimetric method for red blood cell sorbitol $\stackrel{\bar{B}}{\exists}$ dehydrogenase activity G VACA, $P$ ZUNIIGA, C $=$ MEDINA, R ALONSO, G GONZÁLEZ-QUIROGA, RI ORTIZ-DE-LUNA, JM CANTU

A fluorimetric method for the measurement of? pyridoxal and pyridoxal phosphate in human plasma and leucocytes, and its application to patients with sideroblastic marrows GILLIAN P SMITH, DIANA SAMSON, TJ PETERS

Isolation of collagen stimulating factors from? healing wounds RP O'HARE, A FALLON, JFO BRADLEY, J BURNS, J O'D MCGEE

Serum malondialdehyde-like material (MDA-LM) $\stackrel{N}{\Omega}$ in acute myocardial infarction J AZNAR, M TERESA $N$ SANTOS, JUANA VALLES, J SALA

Use of total cholesterol/albumin ratio as an alternative to high density lipoprotein cholesteroko measurement AA NANJI, SUSEELA REDDY

\section{Letters to the Editor}

Book reviews

Some new titles 